\title{
KOMPARASI PENDAPATAN PETANI KARET YANG MENJUAL BOKAR KE PASAR LELANG DAN NON LELANG DI KECAMATAN SEMBAWA KABUPATEN BANYUASIN PROVINSI SUMATERA SELATAN
}

\author{
Comparisson of Rubber Smallholder Revenue which Sold Raw Rubber Material \\ at Auction Market and Non Auction Market at Sembawa Sub-District \\ Banyuasin Distric South Sumatera Province \\ Farulian PURBA $^{1 *}$, Dini ROCHDIANI ${ }^{2}$, dan Eliana WULANDARI ${ }^{3}$ \\ ${ }^{11}$ Program Studi Magister Ilmu Ekonomi Pertanian \\ Fakultas Pertanian Universitas Padjadjaran \\ Jalan Raya Bandung Sumedang KM 21 \\ Jatinangor Sumedang 45363 Jawa Barat \\ *Email: purba.farulian@gmail.com \\ ${ }^{21}$ Badan Pengembangan Sumber Daya Manusia Pertanian \\ Kementerian Pertanian \\ Jalan Harsono RM Nomor 3 Ragunan \\ Pasar Minggu Jakarta Selatan 12550 DKI Jakarta \\ ${ }^{3)}$ SMK Pertanian Pembangunan Negeri Sembawa \\ Jalan Palembang-Pangkalan Balai KM 29 Desa Lalang Sembawa \\ Sembawa Banyuasin Sumatera Selatan 30953
}

Diterima : 9 Juli 2020 / Disetujui : 21 Desember 2020

\begin{abstract}
This study was aimed to determine the differences of rubber smallholder revenue which sold raw rubber material at auction market and non auction market in Sembawa Sub District, Banyuasin District, South Sumatera Province. Sampling was done by probability method. Number of samples were 89 rubber smallholder which consisted of 64 farmers sold raw rubber material at the auction market and 25 rubber smallholders sold raw rubber material at the non-auction markets. Data was analyzed mathematically to evaluate the level of profit and statistically by using independent sample $T$ Test to find the revenue difference of rubber smallholder which sold raw rubber material at auction market and non auction market. The mathematic analysis result showed that rubber smallholder revenue which sold raw rubber material (IDR 299,173.76) was higher than other which sold raw rubber material at non auction market (IDR 252.524). Moreover, statistic analysis indicated that there was difference of rubber smallholder revenue at
\end{abstract}

signicant value as 0,00. If it was compared to significant level at $5 \%$, the signicifant value was lower so it could be summarized that there was significant difference on rubber smallholder revenue.

Keywords: Auction market; non auction; market; revenue

Abstrak
Penelitian ini bertujuan untuk
mengetahui terdapatnya perbedaan antara
pendapatan petani yang menjual hasil bokar
ke pasar lelang dan petani yang menjual
hasil bokar ke pasar non lelang. Penelitian
dilakukan di Kecamatan Sembawa
Kabupaten Banyuasin Provinsi Sumatera
Selatan. Pengambilan sampel menggunakan
metode Probability Sampling. Jumlah sampel
dalam penelitian ini sebanyak 89 petani
karet yang terdiri petani menjual bokar ke
pasar lelang sebanyak 64 responden dan
petani menjual bokar ke pasar non lelang
sebanyak 25 responden. Metode penelitian


dilakukan secara kuantitatif yaitu matematik dan statistik. Analisis data menggunakan analisis matematik untuk mengetahui perbedaan pendapatan petani yang menjual bokar ke pasar lelang dengan petani menjual bokar ke pasar non lelang. Sementara analisis statistik menggunakan Independent Sampel T Test bertujuan untuk mengetahui ada tidaknya perbedaan pendapatan petani yang menjual bokar ke pasar lelang dan petani menjual bokar ke pasar non lelang. Hasil penelitian dengan analisis matematik menunjukan bahwa pendapatan petani yang menjual bokar ke pasar lelang lebih tinggi dari pada petani yang menjual bokar ke pasar non lelang dengan tingkat pendapatan masing-masing sebesar IDR 299.173,76 dan IDR 252.524. Selanjutnya hasil analisis statistik menunjukan terdapat perbedaan pendapatan petani yang menjual bokar ke pasar lelang dan non lelang dengan nilai signifikansi sebesar 0,00. Jika dibandingkan dengan taraf signifikan 5\% maka signifikansi bernilai lebih kecil sehingga dapat disimpulkan bahwa terdapat pengaruh yang nyata terhadap perbedaan pendapatan.

Kata kunci: Non lelang; pasar lelang; pendapatan

\section{PENDAHULUAN}

Karet memiliki peranan sangat penting bagi perekonomian Indonesia. Komoditas karet merupakan salah satu penghasil devisa utama dari sektor perkebunan, total ekspor karet alam sembilan tahun terakhir cenderung berfluktuasi, berkisar antara -13,2518,05\%. Pada tahun 2009 total berat ekspor karet alam Indonesia mencapai 1,9 juta ton dengan total nilai sebesar USD 3,2 milyar, meningkat menjadi 2,9 juta ton pada tahun 2017 dengan total nilai sebesar USD 5,1 milyar (Badan Pusat Statistik [BPS], 2017). Nurmegawati et al. (2014) mengungkapkan bahwa agribisnis karet merupakan sumber lapangan kerja utama bagi lebih dari 1,6 juta orang. Selain itu, agribisnis karet juga berperan penting dalam mendorong pertumbuhan sentra-sentra ekonomi baru di wilayah pedesaan Indonesia, terutama di Sumatera dan Kalimantan.
Perkebunan karet menghasilkan getah karet berupa bahan olah karet (Bokar). Bokar dapat dijumpai dalam bentuk lateks kebun, sit angin, slab tipis, dan lump segar. Ragam produk karet yang dihasilkan dan diekspor oleh Indonesia masih terbatas dan pada umumnya didominasi oleh produk primer (raw material) dan produk setengah jadi. Jika dibandingkan dengan negaranegara produsen utama karet alam lainnya, seperti Thailand dan Malaysia, ragam produk karet Indonesia tersebut lebih sedikit. Sebagian besar produk karet Indonesia diolah menjadi karet remah (crumb rubber) dengan kodefikasi "Standard Indonesian Rubber" (SIR), sedangkan lainnya diolah dalam bentuk Ribbed Smoked Sheet (RSS) dan lateks pekat (Departemen Pertanian, 2007). Produk bokar akan digunakan oleh pabrik karet remah (Standard Indonesian Rubber) yang merupakan bahan baku untuk keperluan industri hilir karet seperti ban, bola, sepatu, karet, karet gelang, mainan dari karet, dan berbagai produk hilir lainnya (Suwardin, 2008).

Najiyati et al. (2012) mengungkapkan bahwa sebagian besar (80\%) kebun karet di Indonesia merupakan kebun rakyat dan karet yang dihasilkan belum diolah secara baik. Rendahnya mutu bokar berdampak terhadap harga yang diterima petani menjadi rendah. Sebagian besar (80\%) bentuk produksi yang dihasilkan petani dalam bentuk slab tebal. Slab tebal ini merupakan mutu paling rendah dari bentuk produksi bokar. Mutu bokar yang rendah juga menyebabkan posisi tawar petani menjadi lemah.

Menurut Mardjoko (2004), pasar lelang merupakan suatu lembaga transaksi komoditas produk yang dilengkapi dengan aturan dan sistem transaksi tertentu menuju pembentukan harga tertinggi secara transparan. Keberadaan pasar lelang komoditas pertanian akan menjadi fasilitator dan intermediasi antar petani (poktan/gapoktan) dan pembeli baik pedagang, pengencer, pengumpul, pedagang besar dan kosumen akhir dengan jaringan pemasaran yang lebih pendek dan transparan. 
Unit Pengolahan dan Pemasaran Bokar (UPPB) Maju Bersama Sembawa m e r u p a n koperasi y a $\mathrm{g}$ menyelenggarakan penjualan bokar melalui sistem lelang. Berdasarkan hasil wawancara dengan pihak manajemen Unit Pengolahan dan Pemasaran Bokar (UPPB) Maju Bersama Sembawa bidang teknis mutu dan produksi pada tahun 2019, masih adanya anggota pasar lelang yang mengabaikan standar mutu yang telah ditetapkan oleh pihak manajemen seperti bokar kotor, adanya campuran tatal (kulit hasil sadapan pohon karet), dan penggunaan bahan penggumpal seperti pupuk KCl. Selain itu, dari 550 anggota Unit Pengolahan dan Pemasaran Bokar (UPPB) Maju Bersama Sembawa terdapat 55-83 orang (10-15\%) anggota yang menjual bokarnya tidak melalui sistem lelang dikarenakan pelaksanaan lelang di Unit Pengolahan dan Pemasaran Bokar (UPPB) Maju Bersama Sembawa hanya dilakukan 1 (satu) kali dalam seminggu sedangkan anggota mampu menjual bokarnya 2 (dua) kali dalam seminggu sehingga anggota menjual bokarnya 1 kali melalui pasar lelang dan satu kali lagi melalui pasar non lelang. Oleh sebab itu, perlu adanya penilaian kinerja panitia lelang dan lembaga lelang.

Petani mengharapkan dengan adanya pasar lelang, harga dan pasar terjamin serta pendapatan petani dapat meningkat. Selama ini, pada penjualan bokar terjadi disparitas harga yang cukup tinggi, keadaan ini dapat dilihat dari selisih harga antara petani yang menjual bokar melalui pasar lelang dan non lelang. Dinas Perkebunan Provinsi Sumsel (2018) mengatakan bahwa apabila petani menjual bokar melalui pasar lelang maka harga bokar mingguan mencapai IDR $9.000 / \mathrm{Kg}$, sedangkan bila menjual langsung (tidak melalui pasar lelang) harga bokar hanya IDR $5.000 / \mathrm{Kg}$. Perbedaan harga ini disebabkan adanya perbedaan mutu bokar yang rendah yang dipasok dari berbagai wilayah sehingga melemahkan posisi tawar petani dan akhirnya harga ditentukan oleh pedagang. Adanya perbedaan harga bokar di tingkat petani akan menyebabkan perbedaan pendapatan petani yang menjual bokar melalui pasar lelang dan non lelang. Pendapatan petani yang menjual bokar melalui pasar lelang diduga lebih tinggi dibandingkan dengan pendapatan petani yang menjual bokar di pasar non lelang.

Penelitian Suriyanto et al. (2018) terdapat perbedaan antara rata-rata biaya petani sistem pemasaran konvensional dengan rata-rata biaya petani dengan sistem pasar lelang. Hal ini disebabkan harga bokar yang di jual petani ke pengepul relatif lebih murah dan kebutuhan petani terhadap modal produksi bokar. Tujuan dari penelitian ini untuk mengetahui apakah terdapat perbedaan pendapatan petani karet yang menjual bokar ke pasar lelang dan pasar non lelang.

\section{BAHAN DAN METODE}

Penelitian dilaksanakan di Kecamatan Sembawa Kabupaten Banyuasin Provinsi Sumatera Selatan. Pertimbangan pemilihan lokasi penelitian dikarenakan terdapat pasar lelang karet. Penelitian dilakukan pada bulan desember 2019.

\section{Penentuan Pengambilan Sampel}

Penelitian ini menggunakan metode survei, yaitu suatu cara memperoleh fakta dan keterangan tentang suatu yang ingin diteliti. Penelitian ini dilakukan terhadap sampel rumah tangga yang menjalankan usahatani karet baik yang menjual bokar ke pasar lelang maupun menjual bokar ke pasar non lelang.

Menurut Sugiyono (2014) berpendapat bahwa sampel adalah bagian dari jumlah dan karakteristik yang dimiliki oleh populasi tersebut. Pengambilan sampel dilakukan karena peneliti memiliki keterbatasan dalam melakukan penelitian baik dari segi waktu, tenaga, dana dan jumlah populasi yang sangat banyak, maka peneliti harus mengambil sampel yang benar-benar representative (dapat mewakili). Pengambilan sampel petani dilakukan dengan proportionate stratified sampling ( pengambilan sampel berstrata proporsional). Jumlah sampel responden ditentukan menggunakan metode slovin (Umar, 2003) dengan menerapkan persamaan sebagai berikut: 
$\mathrm{n}=\frac{\mathrm{N}}{1+\mathrm{N} \cdot \mathrm{e}^{2}}$

Keterangan (Remaks):

$\mathrm{n}=$ ukuran sampel (sample size)

$\mathrm{N}=$ ukuran populasi (population size)

$\mathrm{e}=$ persentase $(\%)$, toleransi ketidaktelitian karena kesalahan dalam pengambilan sampel (tingkat kesalahan dalam pengambilan sampel ini sebesar 10\%) (percentage (\%), tolerance of inaccuracy due to errors in sampling (the error rate in this sampling was 10\%)).
Berdasarkan rumus Slovin tersebut, maka jumlah sampel yang diambil dalam penelitian ini disajikan pada Tabel 1 .

Berdasarkan Tabel 1, diketahui bahwa total populasi sebanyak 788 orang dengan ketepatan yang diinginkan sebesar 10\%, maka diperoleh sampel yang akan diteliti sebanyak 89 orang. Sampel yang digunakan dalam penelitian ini, sebanyak 64 responden untuk petani yang menjual bokar ke pasar lelang dan 25 responden petani yang menjual bokar ke pasar non lelang.

Tabel 1. Populasi dan sampel dalam penelitian ini Table 1. Population and sample were used in the research

\begin{tabular}{llcc}
\hline \multirow{2}{*}{ No } & Objek/Subjek & Populasi & Sampel \\
& Object/Subject & Population & Sample \\
\hline 1 & Petani yang menjual bokar melalui lelang & 533 & 64 \\
2 & Petani yang menjual bokar melalui non lelang & 255 & 25 \\
& Jumlah & 788 & 89 \\
\hline
\end{tabular}

\section{Jenis dan Sumber Data}

Data yang dikumpulkan pada penelitian ini meliputi data primer dan sekunder. Data primer diperoleh dengan melakukan pengamatan langsung ke lokasi penelitian serta wawancara langsung dengan responden menggunakan daftar pertanyaan (kuesioner) yang telah disiapkan. Data sekunder yaitu data yang diambil dari instansi terkait, seperti monografi daerah penelitian, luas area perkebunan karet, produksi dan harga bokar di pasar lelang, UPPB, dan lain-lain yang berkaitan dengan penelitian.

\section{Metode Analisis Data}

Metode analisis yang digunakan adalah metode deskripsi dan kuantitatif. Untuk menjawab tujuan dan hipotesis dilakukan analisis data dengan menghitung analisis pendapatan secara matematik dan analisis uji beda (T-test) secara statistik. Data yang diperoleh kemudian diolah secara tabulasi. Dalam penelitian untuk menganalisis pendapatan petani karet yang menjual bokar baik ke pasar lelang dan non lelang secara matematis dipergunakan rumus sebagai berikut:

$\mathrm{Pd}=\mathrm{TR}-\mathrm{TC}$
Keterangan (Remaks) :

$\mathrm{Pd}=$ pendapatan petani karet (IDR/minggu) (rubber smallholder revenue (IDR/week))

$\mathrm{TR}=$ total penerimaan petani karet (IDR/minggu) (total rubber smallholder revenue (IDR/week))

$\mathrm{TC}=$ total biaya petani karet (IDR/minggu) (total rubber smallholder expense (IDR/week))

Selain itu untuk mengetahui apakah terdapat perbedaan tingkat pendapatan petani yang menjual bokar ke pasar lelang dan petani menjual bokar ke pasar non lelang. Dilakukan pengujian dengan menggunakan uji beda dua rata-rata dengan rumus :

$\mathrm{t}=\frac{\mathrm{X} 1-\mathrm{X} 2}{\sqrt{\frac{(\mathrm{n} 1-1) \mathrm{s} 1^{2}+(\mathrm{n} 2-1) \mathrm{s} 2^{2}}{\mathrm{n} 1+\mathrm{n} 2-2} \times} \frac{1}{\mathrm{n} 1}+\frac{1}{\mathrm{n} 2}}$

Keterangan (Remaks):

$\mathrm{X} 1$ : rata- rata pendapatan kelompok pertama (revenue average offirst group)

$\mathrm{X} 2$ : rata- rata pendapatan kelompok kedua (revenue average of second group)

N1: jumlah sampel kelompok pertama (number of samples of first group)

N2: jumlah sampel kelompok kedua (number of samples of second group) 
$\mathrm{S} 1^{2}$ : deviasi standar kelompok pertama (standard deviation of first group)

$\mathrm{S} 2^{2}$ : deviasi standar kelompok kedua (standard deviation of second group)

Hipotesis penelitian adalah Ho : $\mu 1 \neq$ $\mu 2$. Diduga pendapatan petani yang menjual bokar ke pasar lelang tidak sama dengan petani menjual bokar ke pasar non lelang. Kaidah pengambilan keputusan adalah sebagai berikut :

Jika (t hit $<\mathrm{t}$ tab $\mathrm{a}=5 \% \mathrm{db}=(\mathrm{n} 1+\mathrm{n} 2)-2$ terima Ho)

$(\mathrm{t}$ hit $>\mathrm{t}$ tab $\mathrm{a}=55 \mathrm{db}=(\mathrm{n} 1+\mathrm{n} 2)-2$ tolak Ho).

\section{HASIL DAN PEMBAHASAN}

\section{Kelembagaan Unit Pengolahaan dan Pemasaran Bokar (UPBB) Maju Bersama}

Unit Pengolahan dan Pemasaran Bokar (UPPB) Maju Bersama Sembawa didirikan pada tahun 2011 dan saat itu mulanya hanya beranggotakan enam orang dan tonasenya hanya $1.500 \mathrm{Kg}$. Tetapi semakin lama semakin bertambah anggotanya bahkan sampai sekarang sudah mencapai 550 petani dan tonase rata-rata 40 ton lebih per minggu dan anggota tersebut bukan hanya dari sekitar Sembawa saja tetapi juga berasal dari desa yang lain dan sekarang sudah dibentuk tujuh gabungan kelompok tani (gapoktan).

Gapoktan ini didirikan atas dasar ingin membantu para petani dalam hal penetuan harga jual Bahan Olah Karet (bokar) karena harga bokar antara petani yang satu dengan petani yang lain berbeda, selain itu juga ingin memperbaiki mutu bokar khususnya di Desa Sembawa dan sekitarnya. Sudah menjadi kebiasaan petani dalam mengolah bokar kebanyakan adalah dengan cara yang tidak sesuai rekomendasi, tatal/kulit batang pohon karet turut dicampurkan dengan lateks. Cara penggumpalan lateks juga menggunakan berbagai campuran dengan tujuan supaya mendapatkan hasil yang lebih banyak. Dengan mutu yang sangat rendah tersebut tentu saja Tengkulak (Toke) membeli dengan harga yang sangat rendah bahkan tidak jarang petani selalu dipermainkan oleh Toke.
Melihat kejadian tersebut maka segenap panitia ingin mengubah paradigma petani karet bagaimana supaya kualitas yang awalnya kurang bagus menjadi lebih baik dan sehingga diperoleh harga bokar yang juga semakin tinggi. Disamping itu juga untuk memperpendek mata rantai pemasaran atau tata niaga bokar. UPPB Maju Bersama Sembawa sebagai media bagi petani dengan harapan petani akan merasakan harga bokar yang semestinya tanpa melalui perantara karena pembeli langsung dari pabrik. Dengan hasil yang maksimal maka tentu akan meningkatkan taraf hidup para petani karet.

\section{Biaya Produksi Peserta Lelang Bokar dan Non Lelang di Kecamatan Sembawa}

Menurut Sukirno (1996) biaya merupakan pengorbanan sumber ekonomi yang diukur dengan satuan uang yang telah terjadi untuk tujuan tertentu. Biaya produksi yang dikeluarkan untuk bertani karet di kecamatan Sembawa meliputi biaya tetap, dan biaya tidak tetap. Biaya tetap (fixed cost) adalah biaya yang besarnya kecilnya tidak dipengaruhi oleh besar kecilnya produksi. Rincian biaya tetap yang dikeluarkan oleh petani responden terdiri atas biaya untuk pengadaan pisau sadap, talang, mangkok, ember dan kotak cetak lump. Biaya tidak tetap (variable cost) adalah biaya yang besar kecilnya dipengaruhi oleh besar kecilnya produksi dan sifatnya habis dalam satu kali proses produksi. Biaya tidak tetap petani karet di lokasi penelitian terdiri dari biaya pupuk, herbisida dan tenaga kerja. Rincian pengunaan biaya rata-rata petani karet menjual bokar ke pasar lelang dapat dilihat pada Tabel 2 sebagai berikut.

Tabel 2, memperlihatkan bahwa biaya total rata-rata yang dikeluarkan untuk peserta lelang bokar dan peserta non lelang Kecamatan Sembawa masing-masing IDR 869.346,51 dan IDR 228.985,73 proporsi biaya terbesar yaitu biaya pupuk. Hal ini terjadi karena petani karet memerlukan pupuk yang cukup banyak. Hasil penelitian Azmi et al. (2018) menunjukkan bahwa ratarata biaya operasional produksi paling besar yang dikeluarkan oleh petani anggota dan non anggota UPPB Jaya Bersama di Kabupaten Banyuasin yaitu biaya pupuk sebesar IDR 155.500 untuk anggota UPPB dan IDR 130.000 pada non anggota UPPB. 
Tabel 2. Rata-rata biaya petani karet menjual bokar ke pasar lelang bokar dan non lelang di Kecamatan Sembawa

Table 2. Expense average of rubber smallholder which sold raw rubber material at auction market and non auction market in Sembawa Sub-District

\begin{tabular}{|c|c|c|c|c|}
\hline $\begin{array}{l}\text { Jenis biaya } \\
\text { Expense type }\end{array}$ & \multicolumn{2}{|c|}{$\begin{array}{c}\text { Pasar lelang } \\
\text { Auction market }\end{array}$} & \multicolumn{2}{|c|}{$\begin{array}{c}\text { Pasar non lelang } \\
\text { Non auction market }\end{array}$} \\
\hline Biaya tetap & IDR & $\%$ & IDR & $\%$ \\
\hline Pisau sadap & $3.492,12$ & 0,04 & 1.858 & 0,8 \\
\hline Talang & $5.046,51$ & 0,06 & $2.604,17$ & 0,1 \\
\hline Mangkok & $5.924,1$ & 0,07 & 6.125 & 2,67 \\
\hline Ember & 562,84 & 0,06 & $2.554,19$ & 0,1 \\
\hline Kotak cetak lump & $20.760,14$ & 0,24 & $25.213,17$ & 11,01 \\
\hline Biaya pupuk & IDR & & IDR & $\%$ \\
\hline Urea/SP36 & $146.858,11$ & 16,89 & 35.125 & 15,34 \\
\hline Pupuk KCl & $141.317,57$ & 16,26 & 31.350 & 13,69 \\
\hline Pupuk TSP & $140.912,16$ & 16,21 & $32.474,07$ & 14,18 \\
\hline Pupuk NPK & $195.135,14$ & 22,45 & $45.883,52$ & 20,04 \\
\hline Herbisida & $89.662,16$ & 10,31 & $87.890,84$ & 38,38 \\
\hline Tenaga kerja & IDR & $\%$ & IDR & $\%$ \\
\hline Penyadapan & $31.780,82$ & 0,37 & $38.889,11$ & 16,98 \\
\hline Pemupukan & $51.109,59$ & 0,59 & $15.000,8$ & 6,55 \\
\hline Penyemprotan & $25.675,68$ & 0,3 & 68.125 & 29,75 \\
\hline Angkut ke tempat Penjualan & $12.569,44$ & 0,14 & & \\
\hline Jumlah & $869.346,51$ & 100 & $228.985,73$ & 100 \\
\hline
\end{tabular}

Sumber: Data primer (diolah)

Source: Primary data (processed)

\section{Penerimaan}

Penerimaan yang diperoleh dari kegiatan usahatani akan selalu besar dari biaya yang telah dikeluarkan dalam usahatani tersebut. Semakin besar penerimaan yang diperoleh maka petani akan termotivasi untuk meningkatkan produksinya (Hernanto, 1996). Penerimaan merupakan refleksi dari kinerja produksi dan dinamika harga, artinya besarnya penerimaan ditentukan oleh dua aspek yaitu aspek produksi dan aspek harga, dengan kata lain penerimaan bisa meningkat apabila produksi meningkat walaupun harga tetap atau naik serta walaupun produksi tetap atau kedua aspek tertentu meningkat.

Berdasarkan pengamatan di wilayah penelitian terlihat bahwa petani dapat memanen karet seminggu sekali. Produksi yang diperoleh berkisar antara 80 sampai $150 \mathrm{Kg} / \mathrm{Ha}$ dengan tingkat harga bervariasi tergantung pada kondisi pasar dan kualitas karet. Untuk lebih jelasnya penerimaan hasil petani karet menjual bokar ke pasar lelang dan peserta non lelang dapat dilihat pada Tabel 3.

Tabel 3 Penerimaan rata-rata pada petani menjual bokar ke lelang dan non lelang di Kecamatan Sembawa.

Table 3. Revenue average of rubber smallholder which sold raw rubber material at auction market and non auction market in Sembawa Sub-District

\begin{tabular}{lrr}
\hline \multicolumn{1}{c}{ Uraian } & Peserta lelang bokar & Peserta non lelang \\
Description & Raw rubber material auction participant & Non auction participant \\
\hline Produksi (Kg) & 137,47 & 111,8 \\
Harga (IDR/Kg) & 8.500 & 6.390 \\
Penerimaan (IDR) & $1.168 .520,27$ & 710.384 \\
\hline
\end{tabular}

Sumber: Data primer (diolah)

Source : Primary data (processed) 
Dari hasil penelitian ini diketahui bahwa rata-rata produksi petani karet yang menjual bokar ke pasar lelang lebih ditinggi dibandingkan petani yang tidak menjual bokar di pasar lelang (non lelang). Rendahnya produksi peserta lelang dikarena tidak ada batasan untuk menjual kepada pengepul atau pedagang besar. Terdapat juga perbedaan harga antara pasar lelang dan non lelang. Hal ini dikarenakan kualitas bokar yang dijual ke pasar lelang merupakan kualitas bagus sehingga harga juga lebih tinggi. Sejalan dengan penelitian Stevan et al. (2015) yang mengatakan bahwa lebih besar harga diterima petani yang menjual bokar di pasar lelang daripada menjual ke pasar non lelang. Hal ini disebabkan oleh pasar lelang memiliki saluran tataniaga yang pendek dibandingkan dengan saluran tataniaga pada pasar non lelang.

\section{Pendapatan}

Menurut Santika (1999), setiap akan melakukan kegiatan usahatani, petani tentunya akan selalu berpikir apakah usahanya menguntungkan atau tidak. Perhitungan analisis usahatani merupakan salah satu tolak ukur untuk menghitung keuntungan tersebut. Untuk mengetahui lebih jelas prospek keuntungan petani karet yang menjual bokar ke pasar lelang dan non pasar lelang di Kecamatan Sembawa, berikut pada Tabel 4 disajikan analisis pendapatan petani karet dalam satu penjualan pasar lelang dan non lelang.

Tabel 4. Analisis pendapatan pada petani menjual bokar ke pasar lelang dan non lelang di Kecamatan Sembawa

Table 4. Analysis of rubber smallholder revenue which sold raw rubber material at auction market and non auction market in Sembawa Sub-District

\begin{tabular}{lrr}
\hline \multicolumn{1}{c}{$\begin{array}{c}\text { Uraian } \\
\text { Description }\end{array}$} & $\begin{array}{c}\text { Pasar lelang bokar } \\
\text { Raw rubber material auction } \\
\text { market } \\
\text { (IDR) }\end{array}$ & $\begin{array}{c}\text { Pasar bokar non lelang } \\
\text { Raw rubber material non auction } \\
\text { market } \\
\text { (IDR) }\end{array}$ \\
\hline Biaya & $869.346,51$ & $228.985,73$ \\
Penerimaan & $1.168 .520,27$ & 710.384 \\
Pendapatan & $299.173,76$ & 252.524 \\
\hline
\end{tabular}

Sumber: Data Primer (diolah)

Source : Primary data (processed)

Pada Tabel 4, terlihat bahwa hasil perhitungan analisis pendapatan dari petani yang menjual bokar ke pasar lelang lebih tinggi dengan tingkat pendapatan sebesar IDR 299.173,76 sedangkan untuk petani yang menjual hasil bokar ke pesar non lelang baik menjual kepada pengumpul dan pedagang besar dengan rata-rata tingkat pendapatan sebesar IDR 252.524. Bedanya pendapatan tersebut diakibatkan oleh perbedaan produksi antara petani karet yang menjual hasil bokar ke pasar lelang dan non lelang. Berdasarkan analisis bahwa pendapatan petani karet yang menjual bokarnya baik kepada pasar lelang dan non lelang di Kecamatan Sembawa menguntungkan. Berbeda dengan penelitian yang dilakukan Hermansyah et al. (2014) yang menunjukkan bahwa besarnya pendapatan petani karet Kecamatan Sekernan untuk petani yang menjual hasil bokarnya kepada pasar lelang dengan ratarata pendapatan IDR 4.803.126/per bulan sedangkan petani yang menjual bokarnya ke luar pasar lelang (Toke) sebesar IDR 6.272. $850 /$ per bulan. Sejalan dengan penelitian yang dilakukan oleh Yuswandi et al. (2018) terdapat perbedaan pendapatan petani yang menjual bokar ke kelompok usaha bersama (KUB) dengan petani yang menjual bokar ke non KUB. Hal ini dikarenakan rata-rata produksi dan harga petani menjual ke KUB lebih tinggi dari pada petani yang menjual bokar ke non KUB. 


\section{Analisis Komparasi Pendapatan Petani yang Menjual Bokar ke Pasar Lelang dan Non Lelang}

Komparasi pendapatan merupakan indikator yang paling sering digunakan oleh para ekonom. Untuk mengetahui perbedaan antara petani yang menjual bokar ke pasar lelang dan petani menjual ke pasar non lelang dengan analisis uji beda dua rata-rata dengan tingkat kepercayaan 95\% atau a = 0,05 . Untuk mengetahui pengaruh petani menjual bokar ke pasar lelang dan non lelang terhadap pendapatan dilihat pada Tabel 5 .

Hasil analisis menunjukan p-value untuk perbedaan pendapatan petani karet yang menjual bokarnya kepada pasar lelang dan yang tidak menjual ke pasar lelang namun kepada pengumpul atau pedagang besar dengan nilai 0,000. Jika dibandingkan dengan taraf signifikan 5\% maka p-value bernilai lebih kecil sehingga dapat disimpulkan bahwa terdapat pengaruh yang nyata antara petani yang menjual bokar kepada pasar lelang dan non lelang. Hal ini disebabkan oleh harga penjual bokar ke pasar lelang UPPB Maju Bersama lebih tinggi dibandingkan menjual bokar kepada pengumpul atau pasar non lelang. Sejalan dengan penelitian yang dilakukan Suriyanto et al. (2018) terlihat bahwa terdapat perbedaan antara rata-rata biaya petani yang menerapkan sistem pemasaran konvensional dengan rata-rata biaya petani dengan sistem pasar lelang.

Tabel 5. Hasil analisis perbedaan pendapatan petani menjual bokar pasar lelang dan non lelang di Kecamatan Sembawa

Table 5. Analysis result of rubber smallholder revenue difference which sold raw rubber material at auction and non auction market in Sembawa Sub-District

\begin{tabular}{|c|c|c|c|c|c|c|c|c|c|}
\hline & \multicolumn{5}{|c|}{ Levene's Test for Equality of Variances } & \multicolumn{4}{|c|}{ T-test for Equality of means } \\
\hline & \multirow[t]{2}{*}{$\mathrm{F}$} & \multirow[t]{2}{*}{ Sig } & \multirow[t]{2}{*}{$\mathrm{T}$} & \multirow[t]{2}{*}{ Df } & \multirow[t]{2}{*}{$\begin{array}{c}\text { Sig. } \\
\text { 2-talied }\end{array}$} & \multirow[t]{2}{*}{$\begin{array}{c}\text { Mean } \\
\text { difference }\end{array}$} & \multirow[t]{2}{*}{$\begin{array}{l}\text { Std.error } \\
\text { difference }\end{array}$} & \multicolumn{2}{|c|}{$\begin{array}{l}\text { 95\% confidence } \\
\text { interval of the } \\
\text { difference }\end{array}$} \\
\hline & & & & & & & & Lowe & Upper \\
\hline $\begin{array}{l}\text { Pendapatan Equal } \\
\text { Variances Asummed }\end{array}$ & 7.199 & .000 & 3.165 & 97 & .002 & 49.217 & 15.552 & 18.349 & 80.085 \\
\hline $\begin{array}{c}\text { Equal variabces not } \\
\text { asummed }\end{array}$ & & & 4.942 & 96.036 & .000 & 49.217 & 9.958 & 29.450 & 68.984 \\
\hline
\end{tabular}

\section{KESIMPULAN}

Berdasarkan hasil penelitian dan pembahasan serta hipotesis yang diajukan, maka dapat ditarik kesimpulan sebagai berikut:

1. Besarnya pendapatan petani yang menjual bokar ke pasar lelang di Kecamatan Sembawa rata-rata per minggu sebesar IDR 299.173,76 sedang petani yang menjual bokar ke pasar non lelang rata-rata pendapatan sebesar IDR $62.070,14$.

2. Berdasarkan analisis perbedaan (komparasi) pendapatan petani yang menjual bokar ke pasar lelang dan non lelang dengan uji beda dengan hasil $\mathrm{F}_{\text {hitung }}$ lebih besar dari $\mathrm{F}_{\text {tabel }}$ dan $\mathrm{T}_{\text {hitung }}$ lebih besar dari $\mathrm{T}_{\text {tabel }}$ dengan signifikan 0,00 , dengan keputusan tolak Ho terima $\mathrm{H} 1$, artinya terdapat perbedaan nyata antara petani yang menjual bokar ke pasar lelang dan petani menjual bokar ke pasar non lelang.

Saran yang dapat dikemukakan oleh Penulis adalah sebagai berikut:

1. Agar petani dapat meningkatkan pendapatan diharapkan menjual hasil bokar melalui pasar lelang.

2. Bagi pemerintah diharapkan memberikan bantuan melalui Dinas Perkebunan dan Dinas Perdagangan untuk menyediakan Penyuluh 
Komparasi Pendapatan Petani Karet yang Menjual Bokar Ke Pasar Lelang dan Non Lelang di Kecamatan Sembawa Kabupaten Banyuasin Provinsi Sumatera Selatan

Perkebunan dan memberikan bantuan dalam bibit klon unggul dan melengkapi perasarana Unit Pengolahan dan Pemasaran Bokar (UPPB) Maju Bersama.

\section{UCAPAN TERIMA KASIH}

Penulis mengaturkan puji syukur kepada Allah SWT serta ucapan terima kasih kepada 1) Dr. Ir. Hj. Dini Rochdiani, MS., selaku Ketua Tim Pembimbing 2) Dr. Eliana Wulandari, SP., MM., selaku Anggota Tim Pembimbing yang telah membimbing dan memberikan arahan kepada penulis dalam menyelesaikan riset ini serta 3) kepada Pihak Manajemen Unit Penggolahan dan Pemasaran Bokar (UPPB) Maju Bersama Sembawa yang telah membantu memberikan informasi yang dibutuhkan.

\section{DAFTAR PUSTAKA}

Azmi, N., Kurniawan, A.M., \& Transprasetia, D. (2018). Komparatif pendapatan petani anggota dan non anggota Unit Pengelolaan dan Pemasaran Bokar (UPPB) Jaya Bersama di Desa Biyuku Kecamatan Suak Tapeh Kabupaten Banyuasin. Jurnal TRIAGRO, 3(1), 3446.

Badan Pusat Statistik. (2017). Statistik Karet Indonesia 2017. Jakarta, Indonesia: BPS.

Departemen Pertanian. (2007). Prospek dan Arah Pengembangan Agribisnis Karet. Jakarta, Indonesia: Badan Penelitian dan Pengembangan Pertanian.

Hernanto, F. (1996). Ilmu Usahatani. Jakarta, Indonesia: Penebar Swadaya.

Hermansyah, R., Edison., \& Arby, A. (2014). Analisis komparasi pendapatan usahatani karet yang menjual ke pasar lelang dan luar pasar lelang di Kecamatan Sekerman Kabupaten Muaro Jambi. Jurnal Sosio Ekonomika Bisnis, 17(2), 21-31. https://doi.org/ 10.22437/jiseb.v17i2.2801
Mardjoko. (2004). Pasar Lelang Harapan Baru Memperbaiki Posisi Tawar Petani, www.bappebti.go.id.

Najiyati, S., Danarti., Slamet, R., Murdiatun., \& Damanik, L. (2012). Difusi teknologi pengolahan karet rakyat di kawasan transmigrasi mendukung koridor ekonomi Sumatera. Jurnal Ketransmigrasian, 29(1), 23-33.

Nurmegawati., Afrizon., \& Sugandi, D. (2014). Kajian kesuburan tanah perkebunan karet rakyat di Provinsi Bengkulu. Jurnal Littri, 20(1), 17-26.

Santika, A. (1999). Agribisnis Cabai. Jakarta, Indonesia: Penebar Swadaya.

Sugiyono. (2014). Metode Penelitian Pendidikan Pendekatan Kuantitatif, Kualitatif, dan R\&D. Bandung, Indonesia: Alfabeta.

Suriyanto., Rosnita., \& Yulida, R. (2018). Studi komparasi pemasaran karet sistem lelang dan konvensional dan keberdayaan ekonomi petani karet di Kecamatan Sentajo Raya Kabupaten Kuantan Singingi. Jurnal Sungkai, 6(2), 41-58. https://doi.org/ $10.30606 /$ js.v6i2.1657

Stevan, J., Alamsyah, Z., \& Nainggolan, S. (2015). Analisis efektivitas pasar lelang karet di Kabupaten Bungo Provinsi Jambi. Jurnal Sosio Ekonomika Bisnis, 15(18), 32-42. https://doi.org/ $10.22437 /$ jiseb.v18i1.2814

Sukirno, S. (1996). Pengantar Teori Makroekonomi. Jakarta, Indonesia: Raja Grafindo Persada.

Suwardin, D. (2008). Roadmap Pengolahan dan Pemasaran Hasil Perkebunan Karet. Dinas Perkebunan Provinsi Sumatera Selatan. Palembang, Indonesia: Disbun Prov Sumsel 
Umar, H. (2003). Motode Penelitian: Aplikasi dalam Pemasaran. Jakarta, Indonesia: Gramedia Pustaka Utama.
Yuswandi., Sasmi, M., \& Susanto, H. (2018). Analisis perbedaan pendapatan petani karet dalam memasarkan bokar melalui KUB dan Non KUB di Desa Jalur Patar Kecamatan Sentajo Raya. Jurnal MAHATANI, 1(1), 35-47. 